Article

\title{
Development of an Eco-Friendly Head Impact Protection Device
}

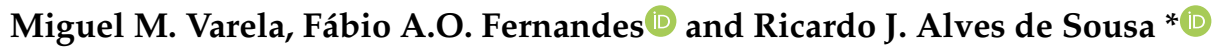 \\ TEMA-Centre for Mechanical Technology and Automation, Department of Mechanical Engineering, \\ University of Aveiro, Campus de Santiago, 3810-193 Aveiro, Portugal; varela@ua.pt (M.M.V.); \\ fabiofernandes@ua.pt (F.A.O.F.) \\ * Correspondence: rsousa@ua.pt
}

Received: 13 March 2020; Accepted: 31 March 2020; Published: 5 April 2020

\begin{abstract}
Nowadays, the number of people practising contact sports has increased. In many of them, using head protective equipment is not mandatory, even if the use of headbands could increase the level of safety regarding several types of traumatic brain injuries. Many commercial solutions are currently available, based on plastic-based foams providing a decent level of protection and comfort to the user. This work introduces the use of agglomerated cork as an eco-friendly alternative to synthetic foams but at least keeping safety levels. Cork is a natural cellular material that has been showing excellent crashworthiness properties. In this study, cork agglomerate density is carefully chosen to be incorporated into a protective headband. Results are compared against three other commercial headbands. For each one, the risk of brain injury was analysed for different injury thresholds and impact energies. The results clearly demonstrate that the cork-based apparel may provide comparable, and in some cases, better performances, outlasting the commercial ones.
\end{abstract}

Keywords: cellular material; finite element analysis; sports safety; brain injuries; head trauma; protective devices; passive safety; sustainable solutions

\section{Introduction}

Soccer, ice hockey and American football are among the most popular sports in the world and where the contact between players is more prone. This fact raises several concerns, especially regarding head injuries. Traumatic brain injuries (TBIs) have been a worrisome issue in the sports world, not just because of the injury itself, but also due to the increasing number of players (including the ones at young ages) and the awareness about long term effects such as chronic traumatic encephalopathy (CTE).

A concussion is one of the most common resulting scenarios for worrying parents, coaches, players, physicians, etc. Tables 1 and 2 present a small summary of studies and results about concussion having in consideration different sport levels, gender and institutions. The results are measured in concussions per 1000 Athletic Exposures (AEs, defined as one athlete participating in one practise or a game where he/she is exposed to the possibility of athletic injury). 
Table 1. Concussion rates in different sports [1].

\begin{tabular}{lll}
\hline Sport & Statistic & Reference \\
\hline Football & High school: 0.48/1000 AEs and reported 1.03/1000 AEs. & {$[2,3]$} \\
& College: estimated 0.52/1000 AEs and reported 0.81/1000 AEs. & {$[4,5]$} \\
& NFL: estimated 4.51/1000 AEs. & {$[6]$} \\
& Multisport: from 0.33 to 0.64/1000 AEs. & {$[7,8]$} \\
\hline Rugby & Nonprofessional players (male): 7.97/1000 player hours. & {$[9]$} \\
& 14\% per 20 hours season (professional athletes. & {$[10]$} \\
& Annual Rugby concussions between 4\% and 14\% (junior players) and & {$[11]$} \\
& between 3\% and 23\% (seniors). & {$[12,13]$} \\
\hline Ice & Junior hockey: from 21.52/1000 AEs in. College: 1.55/1000 AEs. & {$[14]$} \\
\hline Hockey & Female hockey: 0.91/1000 AEs. & {$[15,16]$} \\
& College (male players) 1.08/1000 AEs and 0.52/1000 AEs (female). & \\
\hline Soccer & Concussion rates: $8.6 \%$ (male) and 9.4\% (female). & {$[7,14]$} \\
& Concussion: $0.13 / 1000$ AEs in junior female players to $0.41 / 1000$ AEs in & {$[17,18]$} \\
\hline
\end{tabular}

Table 2. Frequency, distribution, and rates of select injuries for games and practices combined for 15 sports, 1988-1989 to 2003-2004 [14].

\begin{tabular}{lccl}
\hline & $\begin{array}{c}\text { Percentage } \\
\text { All Injuries } \\
(\%)\end{array}$ & $\begin{array}{c}\text { Injury Rate per } \\
\text { 1000 Athletic } \\
\text { Exposures }\end{array}$ & $\begin{array}{l}\mathbf{9 5 \%} \\
\text { Confidence } \\
\text { Interval }\end{array}$ \\
\hline Men's baseball & 2.5 & 0.07 & $0.06,0.08$ \\
\hline Men's basketball & 3.2 & 0.16 & $0.14,0.17$ \\
Women's basketball & 4.7 & 0.22 & $0.20,0.17$ \\
\hline Women's field hockey & 3.9 & 0.18 & $0.15,0.21$ \\
\hline Men's football & 6.0 & 0.37 & $0.36,0.38$ \\
\hline Women's gymnastics & 2.3 & 0.16 & $0.12,0.20$ \\
\hline Men's ice hockey & 7.9 & 0.41 & $0.37,0.44$ \\
Women's ice hockey & 18.3 & 0.91 & $0.71,1.11$ \\
\hline Men's lacrosse & 5.6 & 0.25 & $0.23,0.29$ \\
Women's lacrosse & 6.3 & 0.25 & $0.22,0.29$ \\
\hline Men's soccer & 3.9 & 0.28 & $0.25,0.3$ \\
Women's soccer & 5.3 & 0.41 & $0.38,0.44$ \\
\hline Women's softball & 4.3 & 0.14 & $0.12,0.16$ \\
\hline Men's wrestling & 3.3 & 0.25 & $0.22,0.27$ \\
\hline Men's spring football & 5.6 & 0.54 & $0.5,0.58$ \\
\hline Total concussions & 5.0 & 0.28 & $0.27,0.28$ \\
\hline
\end{tabular}

Regarding young athletes, there is a higher incidence despite the small risk factors (less exposure and fewer cumulative concussions) [3,17]. Indeed, high school players may be at greater risk given their lack of experience to avoid unnecessary contacts [2]. Another important factor in the concussion mechanism is the location of the head impact. Some studies concluded that specific head regions are more prone to injuries, as indicated in Table 3.

Regarding gender influence, female incidence is higher $[7,8,14,17-20]$, excepting lacrosse, where concussion was predominant for male players $[8,14,16,18,21]$. Direct contact (impacts) affected $72 \%$ of men and a much lower $41 \%$ of women [22]. 
Table 3. Annual concussion data ${ }^{a}$ (and 95\% CIs), for American football players, regarding different school years and impact location [23].

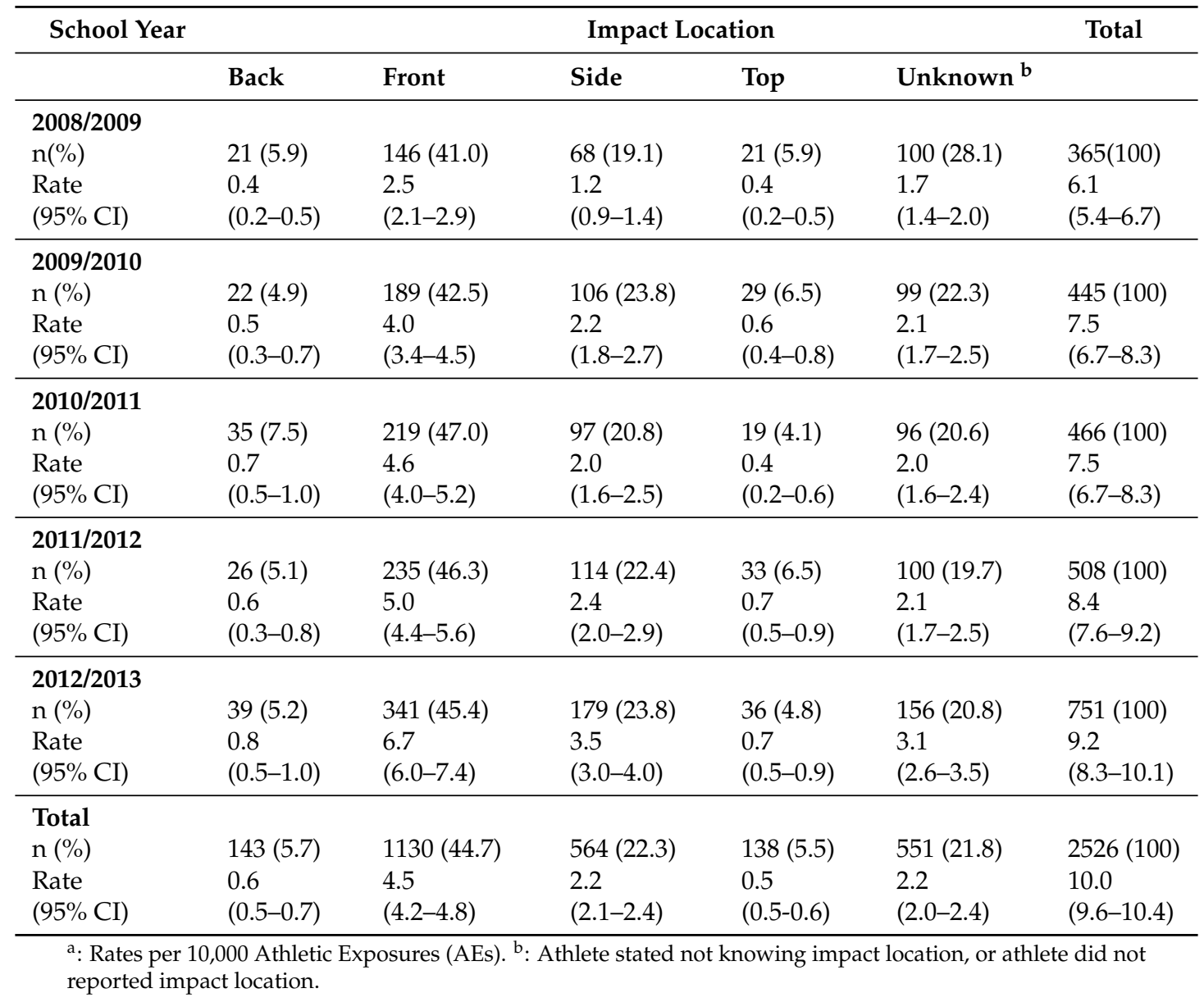

From Table 3, it becomes clear that most impacts occur at the forehead (44.7\%), followed by the lateral (22.3\%), back (5.7\%), and top (5.5\%) impacts. An additional 551 concussions $(21.8 \%)$ had an unknown impact location. The highest rate of concussions resulting from player-to-player collisions was in competition [23]. In this sense, the use of a headband improves dramatically the possibilities of protecting an injury site in case of sports that traditionally do not have head protection devices (e.g., soccer, field hockey).

In fact, headbands are an excellent alternative to classic helmets that could be used in sports where head protection is not required/mandatory and where a helmet would certainly decrease the players' performance. Commercial headbands cover around $50 \%-55 \%$ of the head being made of synthetic cellular materials with the objective to reduce impact force. Under compressive strains, cellular materials are able to undergo very large strains keeping an almost constant and relatively low-stress level (the so-called plateau) until the material gets completely packed (densification stage). Such features allow them to absorb large amounts of energy [24].

Following the United Nation's 2030 agenda of the sustainable development goals, there is significant pressure on the producers to provide sustainable and eco-friendly alternatives to the current market solutions. Cork is mainly a visco-elastic cellular material, being capable to absorb considerable amounts of deformation energy. The initial undeformed shape is practically entirely recovered after unloading, a desirable feature regarding multi-impact scenarios [24,25]. In addition, for cork agglomerates, it is perfectly possible to tune its mechanical properties, by changing density or binder type [26,27]. These features make cork an ideal substitute for synthetic cellular materials [25,28]. 
The research herein presented intends to assess agglomerated cork as an energy-absorbing material to be used in headbands. Three types of cork agglomerates and three commercial headbands were experimentally tested. After its characterisation and numerical modelling, virtual testing inferred about the effectiveness of each particular solution from the kinematic and biomechanical points of view. For the latter, the use of a finite element head model provided an insight about the possibility of sustaining traumatic brain injuries (TBIs) for a given test case involving a head impact with headband protection.

\section{Material and Methods}

Three commercial headbands with distinct price tags and material densities and three cork agglomerates were tested. In order to perform mechanical tests, more specifically uniaxial compressions, a representative piece of material was extracted from the commercial headbands, as depicted in Figure 1. Cork agglomerates in three different densities were provided by Amorim Cork Composites (ACC, Mozelos, Portugal).
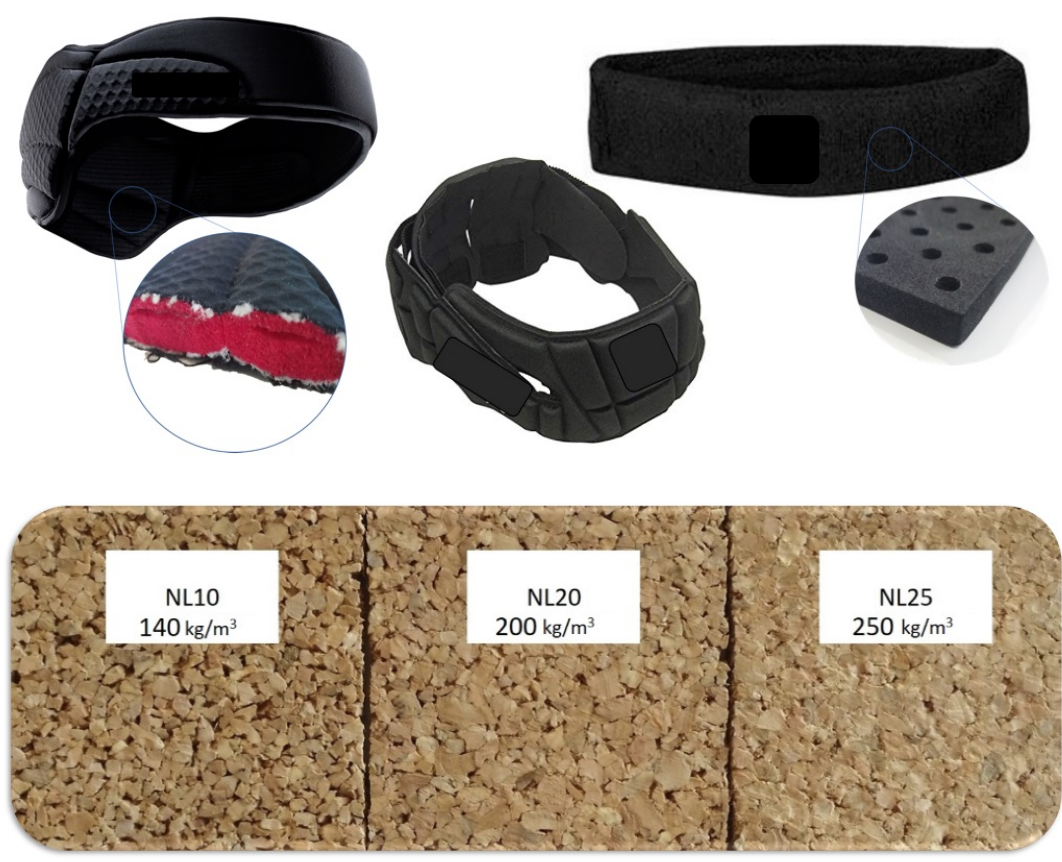

Figure 1. Commercial headbands and cork agglomerates.

The padding materials present in commercial headbands ranged from polyurethane (PU) and polyethylene (PE) foams to Vinyl Nitrile (VN) or Expanded Polypropylene (EPP). In order to not disclose brand names, commercial headbands were denoted as Headband A, B and C, whereas cork agglomerates kept commercial denominations NL10, 20 and 25. A summary of material densities (average from three measurements) is given in given in Table 4.

Three samples from each product were tested. They were removed preferably from the forehead area of the headbands; firstly, because the product area is generally larger there; secondly, from Table 3, it is the head zone where impact likeliness is also bigger. At first, a quasi-static uniaxial compression test was performed using a Shimadzu universal testing machine. Given the limited size of the samples extracted it was not possible to follow any standard. Nevertheless, the parameters were chosen carefully as shown in Table 5. 
Table 4. Materials densities.

\begin{tabular}{lc}
\hline Sample & Density $\left(\mathbf{k g} / \mathbf{m}^{\mathbf{3}}\right)$ \\
\hline Agglomerate Cork: & \\
NL10 & 140.00 \\
NL20 & 193.53 \\
NL25 & 234.12 \\
\hline Commercial Headband: & \\
A & 64.90 \\
B & 309.00 \\
C & 218.00 \\
\hline
\end{tabular}

Table 5. Quasi-static test parameters.

\begin{tabular}{ll}
\hline Parameters & Value \\
\hline Diameter of the compressive actuator & $40 \mathrm{~mm}$ \\
Velocity & $2 \mathrm{~mm} / \mathrm{min}$ \\
Cork samples thickness & $10(2) \mathrm{mm}$ \\
A,B,C samples thickness & $12(2) \mathrm{mm}$ \\
\hline
\end{tabular}

Figure 2 presents uniaxial compressive strain-stress curves for all materials under analysis. Tests were repeated at least three times. It became evident that after the initial elastic deformation, the so-called plateau stage was developed under lower stresses for synthetic foams A, B and C. NL10, given its lower density, was the cork agglomerate yielding lower plateau stresses and later densification strain. In fact, NL10 showed compatible mechanical response compared to commercial headbands. NL20 and NL25 showed more stiff behaviour, exceeding stress values of 1 MPa for very low strain values, which were not compatible with an application where impact energy must be sustained at low-stress levels.

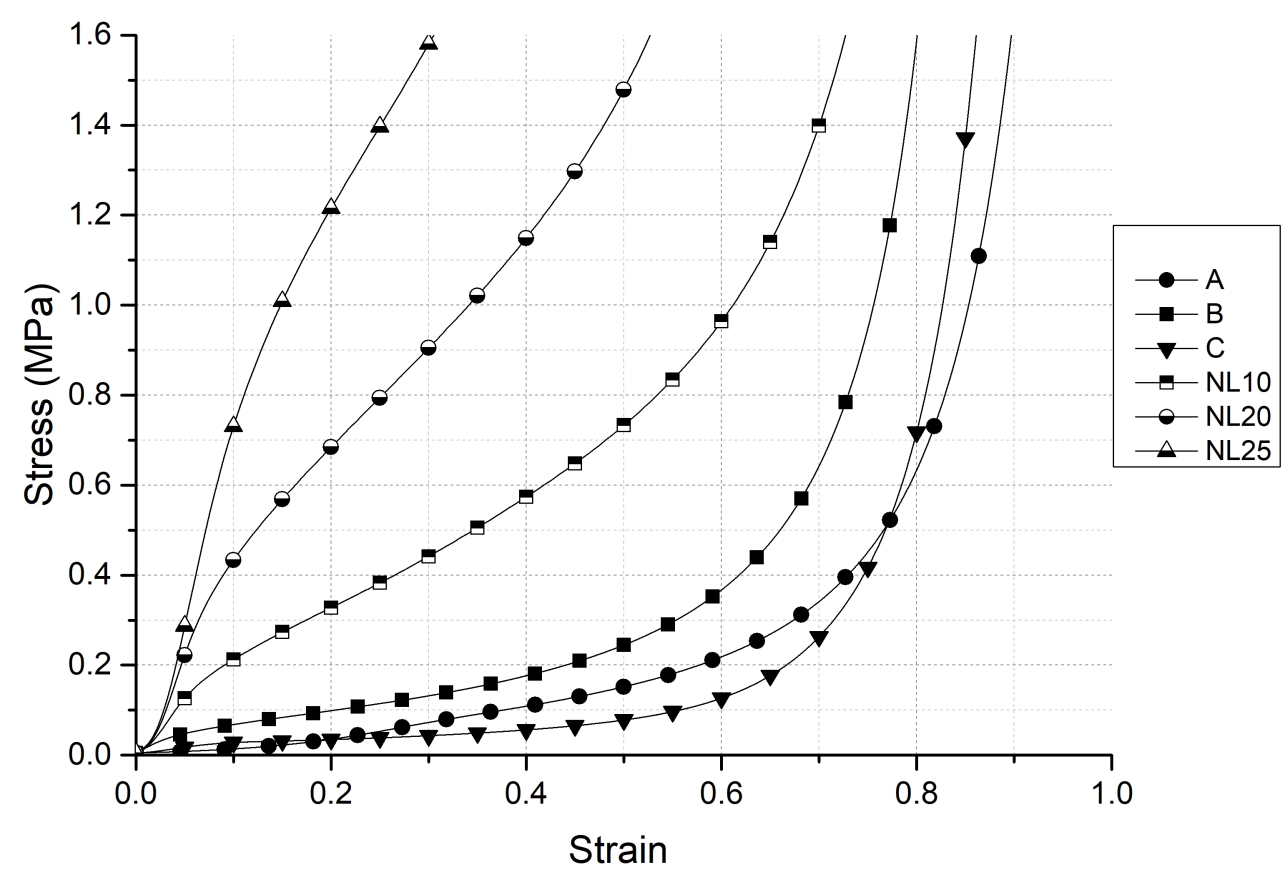

Figure 2. Stress-strain curves in quasi-static uniaxial compression test.

In fact, NL20 and NL25 were discarded as potential materials for the headband device. By setting a threshold of $50 \%$ strain, it was possible to conclude that cork could absorb more energy per unit volume than the synthetic foams used in the market headbands, but at the expense of larger reaction 
forces. Subsequently, NL10 was tested against synthetic foams in dynamic conditions. Similarly to quasi-static tests, dynamic tests did not follow any standard due to the samples' limited thickness.

Dynamic loading was carried out in a guided drop tower apparatus (Figure 3). The $20 \mathrm{~kg}$ impactor was raised to the desired height. An encoder monitored the positions and a uniaxial load cell was connected to the movable system, transmitting reaction force data to the acquisition software. Finally, a Butterworth type filter eliminated part of the noise yielding a smoother curve.

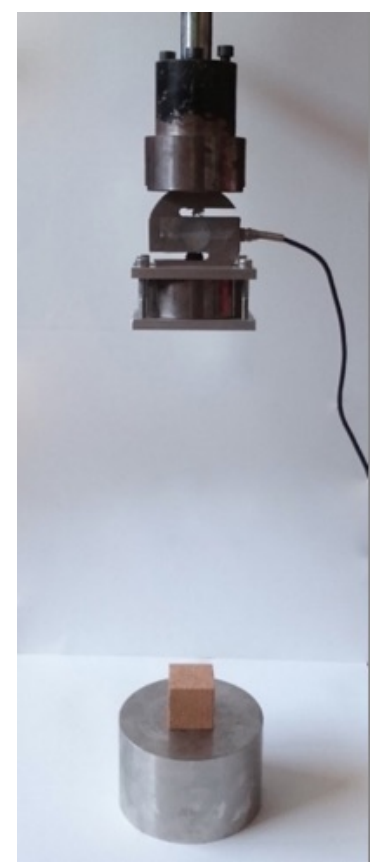

Figure 3. Guided droptower test machine.

Figure 4 presents the dynamic stress-strain curves. Tests were repeated at least three times. Compared to quasi-static ones, the stress-strain curves presented a higher stress level for the same strain values, which is common in cellular materials due to their strain-rate sensitivity between quasi-static and dynamic levels. However, the way each material response varied with the deformation speed was interesting: it was possible to check that material from headband B was much more sensitive to strain-rate than the others. Cork NL10 material response was, in fact, more close to synthetic materials under dynamic loads, which shows the compatibility and capacity of cork regarding this kind of applications. A strain threshold of 0.5 also made evident that headband B's material became too stiff under quick compression, reaching early densification and possibly increasing the risk of injury by transmitting higher reaction forces to the head. Given the lower density of Headband A's material, it had a lower capacity to absorb impact energy, whereas C-type headband and NL10 cork presented a good compromise between densification strain and plateaus stress.

The overall observation of quasi-static and dynamic tests made clear the outstanding capabilities of cork agglomerates for energy absorption purposes, especially in the dynamic regime. Agglomerated cork could absorb more energy (per volume) than the materials from commercial headbands. The B-headband foam had early densification due to its high density. Inside the group of the synthetic foams, C-type presented the best performance. In addition, NL10 showed promising potential in a dynamic situation. 


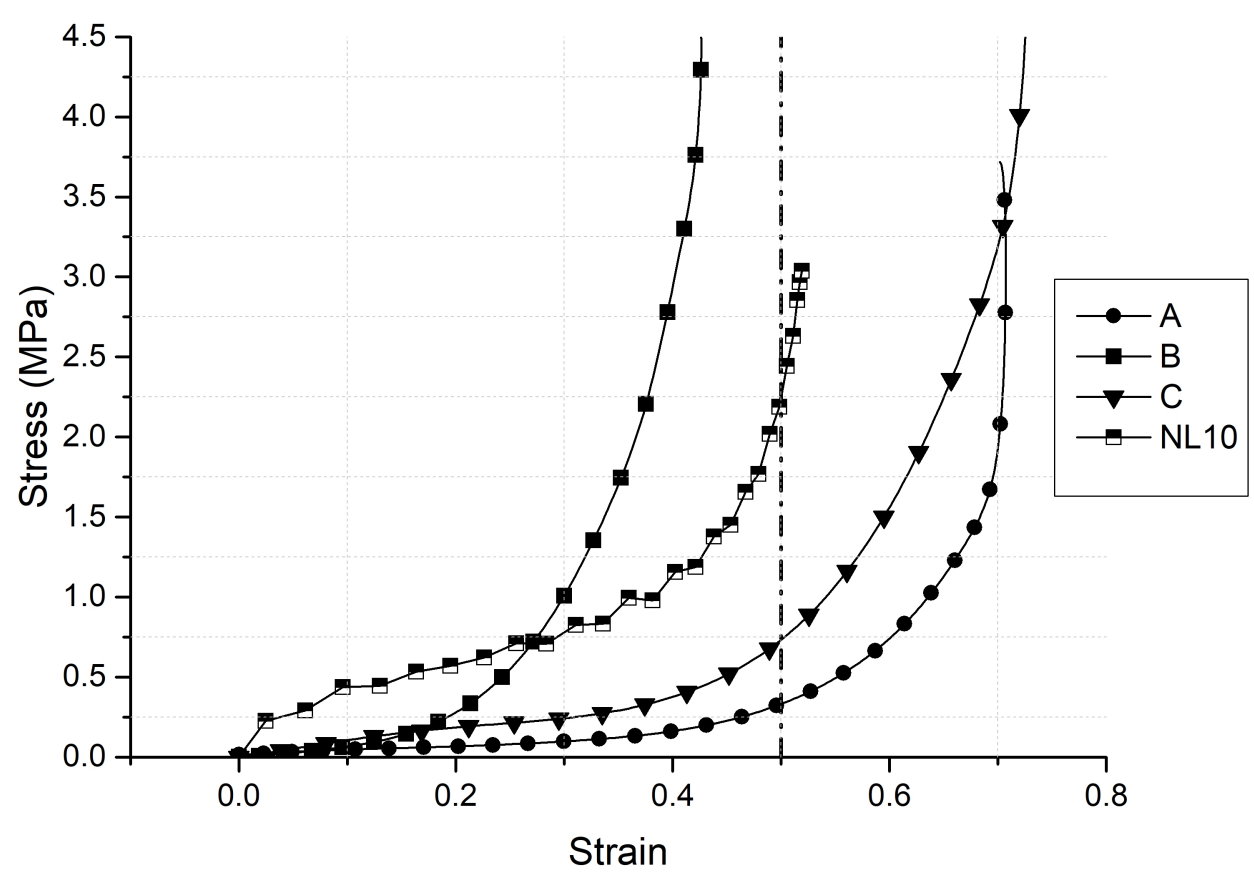

Figure 4. Stress-strain curves from dynamic compression tests.

\subsection{Constitutive Modelling}

For product development purposes, it becomes important to provide reliable constitutive numerical models to represent the materials tested previously. In this work, all the numerical modelling resorted to finite element techniques within the commercial package Abaqus [29]. An extensive and versatile material library is provided, including material models that can simulate the mechanical behaviour of a great variety of cellular materials.

The hyperelastic constitutive model is mostly employed for materials displaying an immediate nonlinear elastic reaction to applied loads, keeping this behaviour to large strains. Well-known examples are latex or any other elastomer [29]. Hyperelasticity is described using strain energy potentials, which in simple terms, defines, per unit volume in the undeformed configuration, the strain energy stored in the material. Usually, the strain energy is a function of the strain components at the material point. However, there are numerous strain energy potentials accessible from materials libraries, able to model isotropic elastomers: the Arruda-Boyce, Marlow, Mooney-Rivlin, Neo-Hookean, Ogden form, polynomial/reduced polynomial, among others [29]. In the present work, two different models were used: the reduced polynomial (Equation (1)) and Ogden form (Equation (4)). The employed reduced polynomial strain energy potential follows as:

$$
U=\sum_{i=1}^{N} C_{i 0}\left(\bar{I}_{1}-3\right)^{i}+\sum_{i=1}^{N} \frac{1}{D_{i}}\left(J^{e l}-1\right)^{2 i}
$$

Being $U$ the strain energy (per reference volume); $N$ is an integer (the polynomial order); $C_{i 0}$ and $D_{i}$ are parameters depending on temperature; $\bar{I}_{1}$ is the first strain invariant (deviatoric):

$$
\bar{I}_{1}={\overline{\lambda_{1}}}^{2}+{\overline{\lambda_{2}}}^{2}+{\overline{\lambda_{3}}}^{2}
$$

$\overline{\lambda_{i}}=J^{-\frac{1}{3}} \lambda_{i}$ refers to the deviatoric stretches whereas $J$ refers to the total volume ratio; $J^{e l}$ is the elastic counterpart and $\lambda_{i}$ are the principal stretches. Finally, the initial shear and bulk moduli are:

$$
\mu_{0}=2 C_{10}, \quad K_{0}=\frac{2}{D_{1}}
$$


The Ogden form of the strain energy potential follows as:

$$
U=\sum_{i=1}^{N} \frac{2 \mu_{i}}{\alpha_{i}^{2}}\left({\overline{\lambda_{1}}}^{\alpha_{i}}+{\overline{\lambda_{2}}}^{\alpha_{i}}+{\overline{\lambda_{3}}}^{\alpha_{i}}-3\right)+\sum_{i=1}^{N} \frac{1}{D_{i}}\left(J^{e l}-1\right)^{2 i}
$$

where $\bar{\lambda}_{i}$ points to the deviatoric principal stretches $\bar{\lambda}_{i}=J^{-\frac{1}{3}} \lambda_{i} ; N$ is again(the polynomial order; $\mu_{i}, \alpha_{i}, D_{i}$ translate temperature-dependent parameters. The initial shear and bulk moduli in the case of Ogden form follows as:

$$
\mu_{0}=\sum_{i=1}^{N} \mu_{i}, \quad K_{0}=\frac{2}{D_{1}}
$$

The Hyperfoam material model present in Abaqus library is isotropic and nonlinear. It is typically employed to model elastomeric foams showing hyperelastic behaviour. It is commonly used in finite-strain applications, where compressive deformations can reach up to $90 \%$. Again, it derives from a strain energy potential, as follows:

$$
U=\sum_{i=1}^{N} \frac{2 \mu_{i}}{\alpha_{i}^{2}}\left[\hat{\lambda}_{1}^{\alpha_{i}}+\hat{\lambda}_{2}^{\alpha_{i}}+\hat{\lambda}_{3}^{\alpha_{i}}-3+\frac{1}{\beta_{i}}\left((J)^{-\alpha_{i} \beta_{i}}-1\right)\right]
$$

being $N$ the polynomial order, while $\mu_{i}, \alpha_{i}$, and $\beta_{i}$ temperature-related parameters;

$$
\hat{\lambda}_{i}=\left(J^{t h}\right)^{-\frac{1}{3}} \lambda_{i} \longrightarrow \hat{\lambda}_{1} \hat{\lambda}_{2} \hat{\lambda}_{3}=J^{e l}
$$

where $J^{e l}$ and $J^{t h}$ are the elastic and thermal volume ratios. The coefficients $\mu_{i}$ are linked to the initial shear modulus, $\mu_{0}$, as follows:

$$
\mu_{0}=\sum_{i=1}^{N} \mu_{i}
$$

whereas the initial bulk modulus, $K_{0}$, comes as:

$$
K_{0}=\sum_{i=1}^{N} 2 \mu_{i}\left(\frac{1}{3}+\beta_{i}\right)
$$

For each term in the energy function, $\beta_{i}$ determines the compressibility degree. $\beta_{i}$ is also related to the Poisson's ratio, $v_{i}$ :

$$
\beta_{i}=\frac{v_{i}}{1-2 v_{i}}, \quad v_{i}=\frac{\beta_{i}}{1+2 \beta_{i}}
$$

Doing so, if $\beta_{i}$ is equal for all the equation terms, there will be a single value for the Poisson's ratio, $v$, valid for all finite logarithmic principal strains.

Regarding geometry, the numerical model is composed by a deformable solid (only $1 / 4$ modelled due to symmetry), which represents the material sample and by two discrete rigid shells that represent the impactor and the ground anvil (Figure 5). The elements used in the deformable body were hexahedrons with reduced integration and hourglass control (C3D8R). Mesh size was chosen in order to prevent any possibly numerical pathology such as locking and/or hourglassing [30].

Table 6 summarises the optimum choice of the polynomial order. Poisson's ratio values are also reported. They are consistent with the experimental observations, being null due to the absence of lateral deformation during uniaxial compression. On the other hand, the SE potential order was based on the material calibration analysis carried. The orders indicated in Table 6 were the ones that enabled a better agreement with the experiments. Remaining input data consisted of the experimental uniaxial compressive stress-strain data, directly inserted as data points in the material card. 


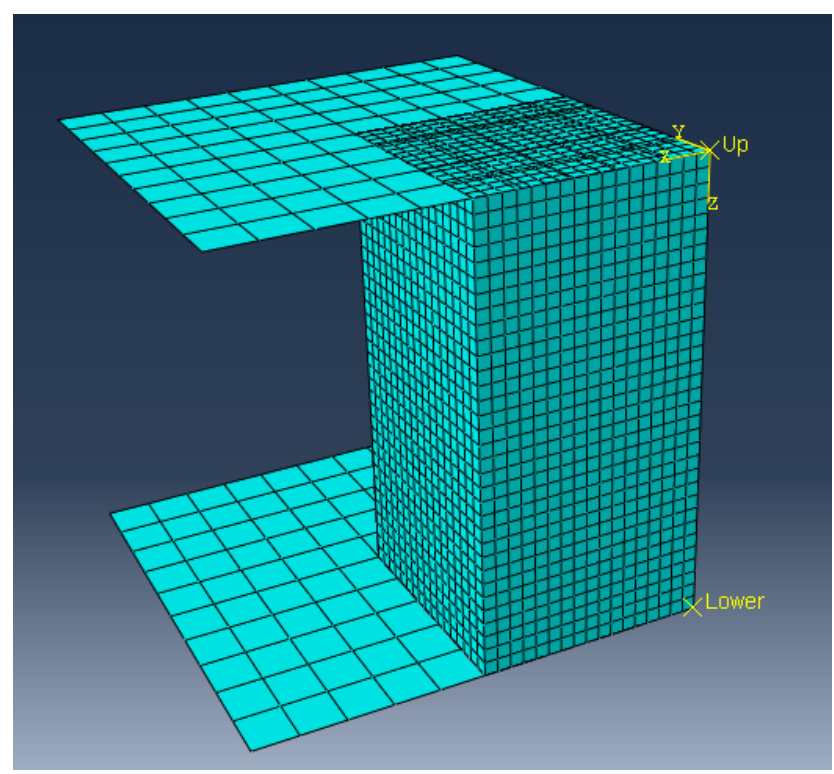

Figure 5. Numerical model to simulate the dynamic tests.

Table 6. Constitutive parameters for dynamic numerical tests.

\begin{tabular}{llcc}
\hline Material & Model & Strain Energy Potential Order & Poisson's Ratio \\
\hline NL10 & Hyperfoam & 3 & 0 \\
A & Ogden & 2 & 0 \\
C & Reduced Polynominal & 6 & 0 \\
B & Reduced Polynominal & 5 & 0 \\
\hline
\end{tabular}

Figure 6 presents the comparison between the simulated and the experimentally measured stress-strain curves, depicting a good match between them for each material.

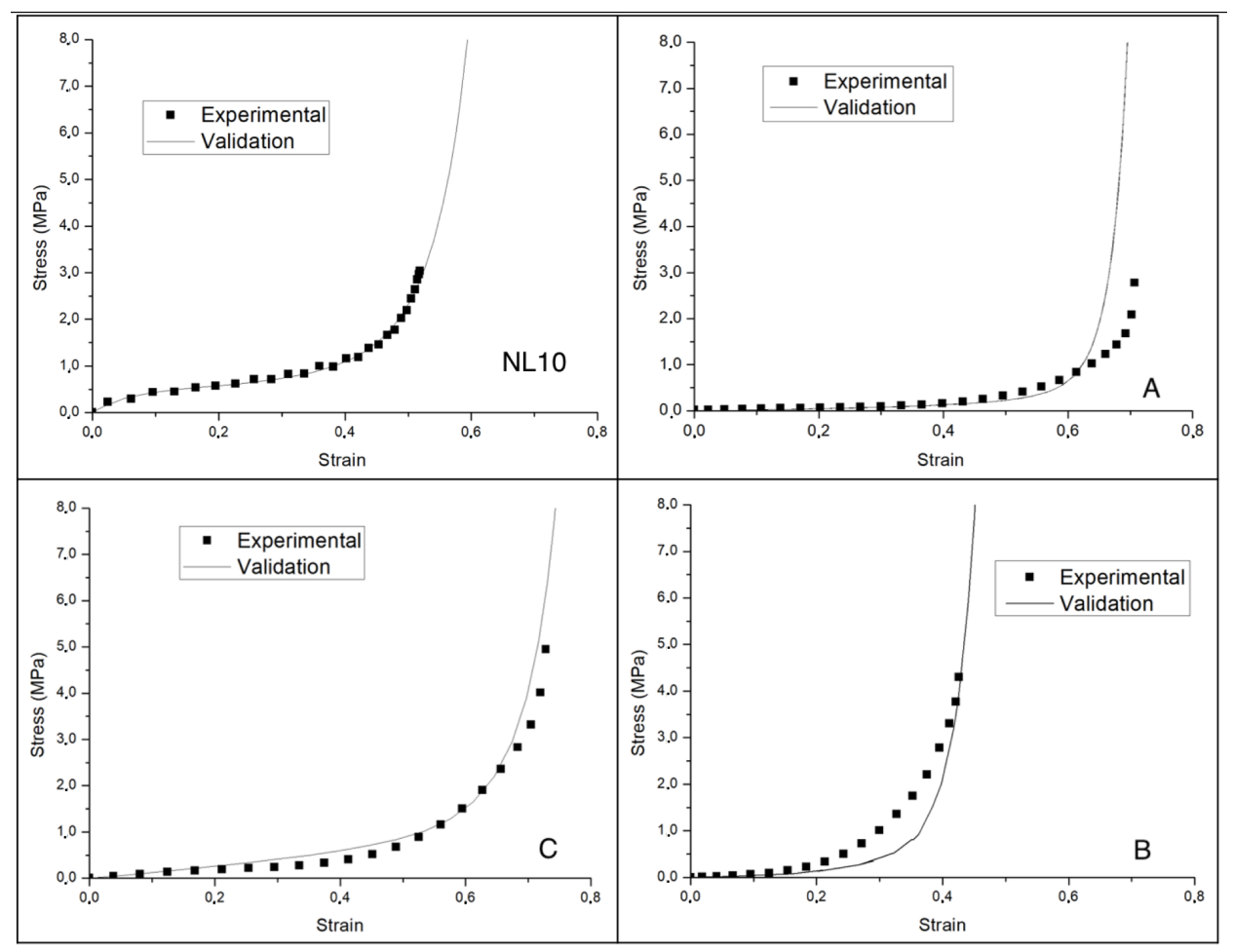

Figure 6. Dynamic test numerical validation for all the materials under study. 


\subsection{Headband Developments}

A simple headband was developed, being $50 \mathrm{~mm}$ wide and $10 \mathrm{~mm}$ thick. The dimensions are consistent with the commercial models. It was fitted to the headform, as shown in Figure 7. The kinematic contact algorithm with a friction coefficient of 0.5 was used to prevent the headband from sliping out of the headform. The objective of this simulation was to impact the system headform-headband against a rigid wall and extract the acceleration measured at the headform's center of mass, for different headband materials and impact velocities. The selected headform is usually employed in helmet testing, specifically in ECE 22.05 for motorcycle helmets. The inertial moments of this $5.6 \mathrm{~kg}$ headform are presented in the Table 7 [31,32]. Table 8 details the formulations for all the parts used in the impact simulation.

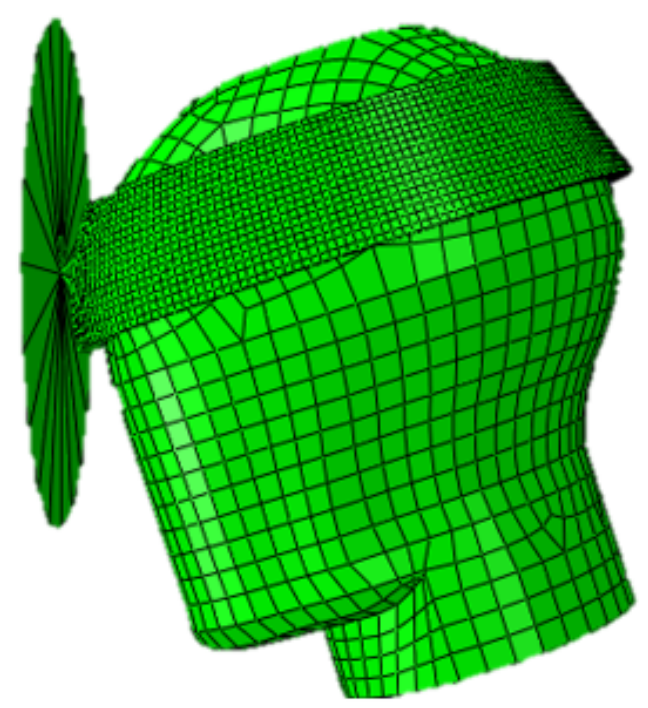

Figure 7. Impact test scheme.

Table 7. Moments of inertia of the headform.

\begin{tabular}{cccc}
\hline & $I_{x x}\left[\mathrm{~kg} \cdot \mathrm{cm}^{2}\right]$ & $I_{y y}\left[\mathrm{~kg} \cdot \mathrm{cm}^{2}\right]$ & $I_{z z}\left[\mathrm{~kg} \cdot \mathrm{cm}^{2}\right]$ \\
\hline Moments of inertia & 286 & 338 & 209 \\
\hline
\end{tabular}

Table 8. Details of the numerical model headform-headband system for impact test simulation.

\begin{tabular}{ccc}
\hline Part & Type of Part & Element \\
\hline Headband & Deformable & C3D8R \\
Headform & Discrete Rigid & R3D4 \\
Ground/Wall & Analytic Rigid & - \\
\hline
\end{tabular}

Several different impact energy values were tested (Table 9), aiming to recreate several sports impacts (Figure 8), and help analysing the materials behaviour under lower and higher impact energies. Assuming the mass of the headform of $5.6 \mathrm{~kg}$, the initial velocity necessary to achieve each impact energy level was calculated. Table 9 summarises the energy values and corresponding velocities. 
Table 9. Impact energy and velocity values.

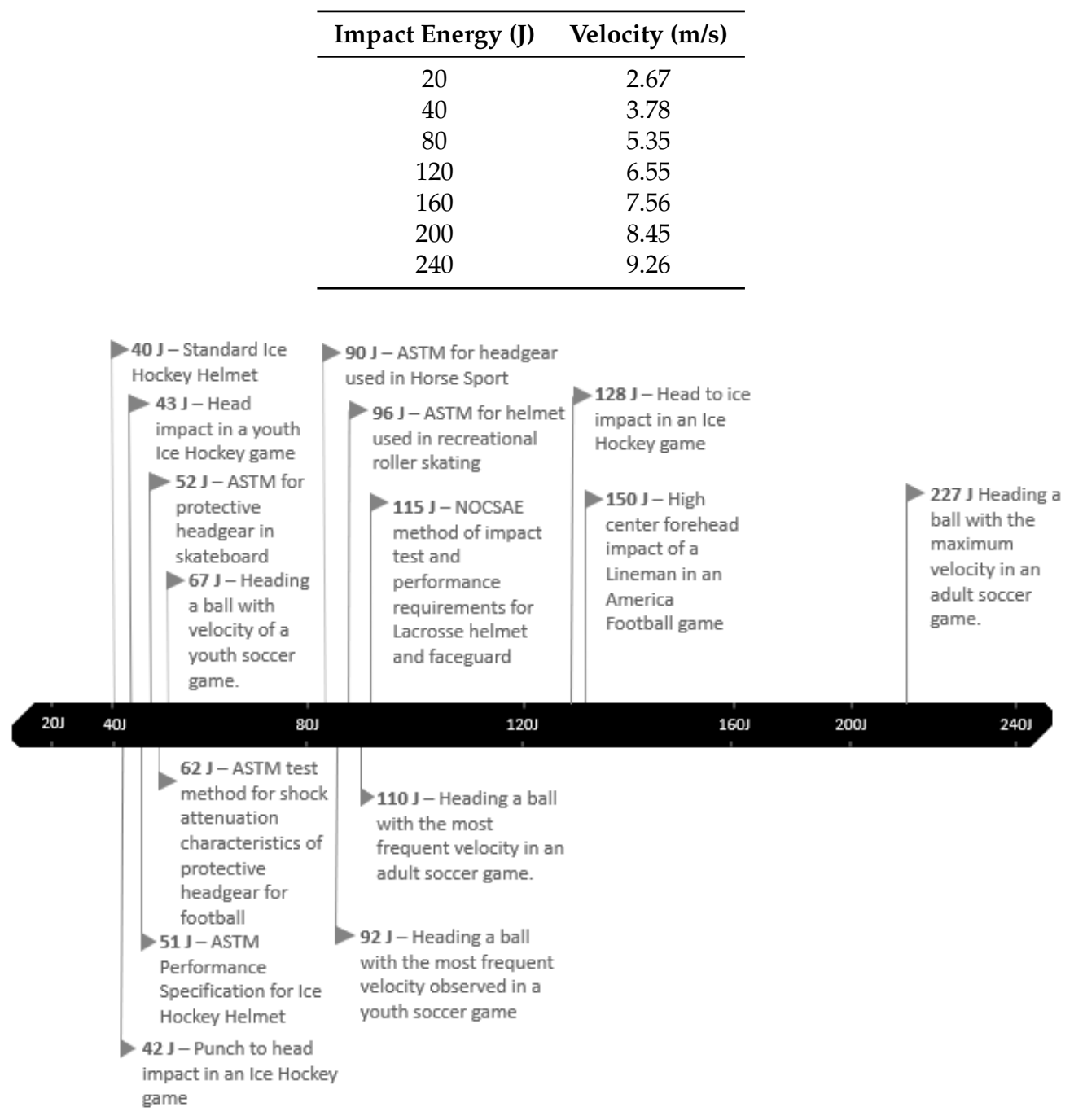

Figure 8. Impact energy in different situations [33-37].

\section{Results}

\subsection{Acceleration Profiles}

The simulated bell-shaped, acceleration-time curves for five different energy levels is presented in Figure 9. Regarding crashworthiness, acceleration vs. time curves must preferably have larger bases and lower heights, meaning lower peak accelerations in a larger time-span, meaning that injury thresholds such as the HIC (Head Injury Criterion) will be less critical [38].

In the presented bell-shaped curves, the trend was quite similar for all of the five energy levels under study. The worst performance was attained by the low-density, commercial headband A in all the cases. For low energy impacts (20 J and $40 \mathrm{~J}$ ), the denser B-type commercial headband presented higher peak accelerations and shorter pulses, while the C-type headband and cork-based one presented a good compromise between pulse and peak accelerations, with intermediate behaviours. As impact energy levels increase, the response of B, C and cork headbands became much more similar.

For an alternative qualitative valuation of headbands' performance the evolution of the Peak Linear Acceleration (PLA) is shown on Figure 10. Besides the natural trend of increasing PLA values with impact energy, once again the poorer performance of low density A-type headband was noticeable, while the other three (Cork, B and C) presented similar responses in terms of PLA. 

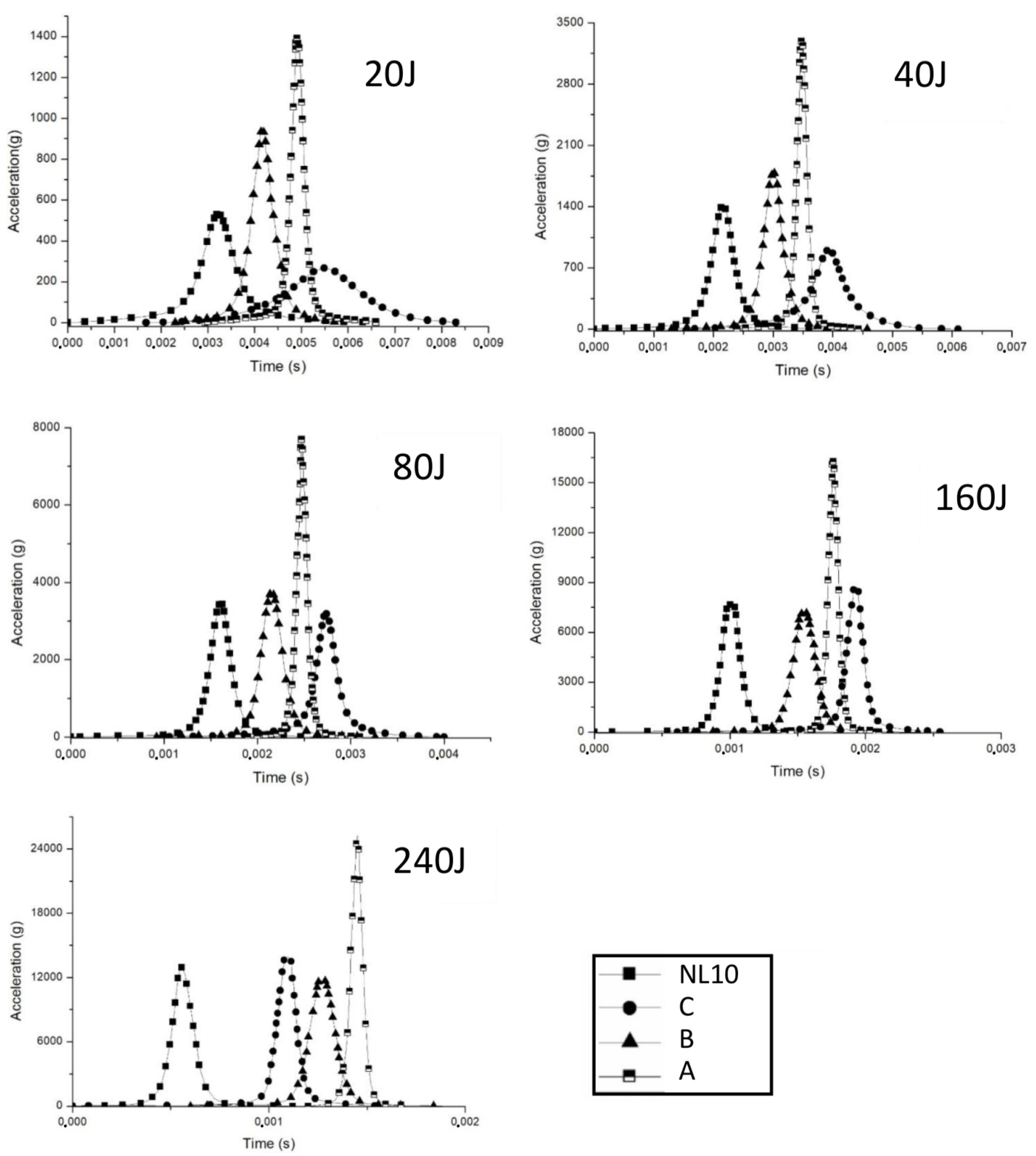

Figure 9. Headform impact test result for the studied headbands.

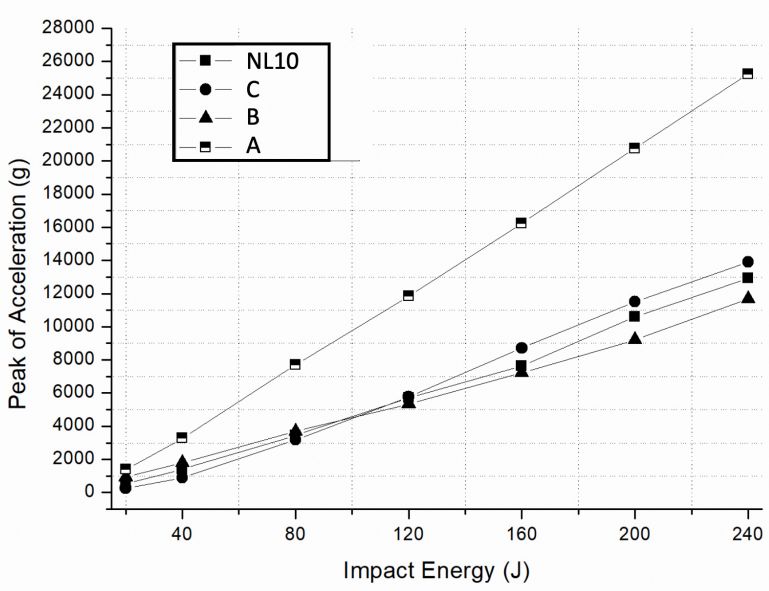

Figure 10. Peak Linear Acceleration (PLA) results for each material in the headform impact test. 


\subsection{Biomechanical Analysis}

In order to perform the injury risk analysis, the YEAHM model developed at the University of Aveiro was employed $[39,40]$. The three Cartesian components of linear acceleration (curves in Figure 9 for $20 \mathrm{~J}$ ) were used to drive the FE head model. These impacts were simulated using a rigid headform and a rigid wall with the headband in between attenuating the impact. These conditions are far from realistic leading to overestimation of peak accelerations, which is the main limitation of this analysis. Bearing this in mind, the following consideration focused on the lower energy impact, $20 \mathrm{~J}$ of energy, in which the headbands performance showed larger differences.

Brain response was checked in terms of strain, pressure and von Mises stress. Using a set of thresholds reported in the literature, such as the ones condensed in [41], the probability of Mild Traumatic Brain Injury (MTBI), Diffuse Axonal Injury (DAI) and concussion occurring was evaluated. Some of these values refer to a single area of the brain like the corpus callosum (Figure 11), where it was possible to determine a $50 \%$ probability to occur concussion and DAI. Basically, almost the entire corpus callosum was under an excessive level of deformation, reaching a maximum principal strain higher than 0.21 .

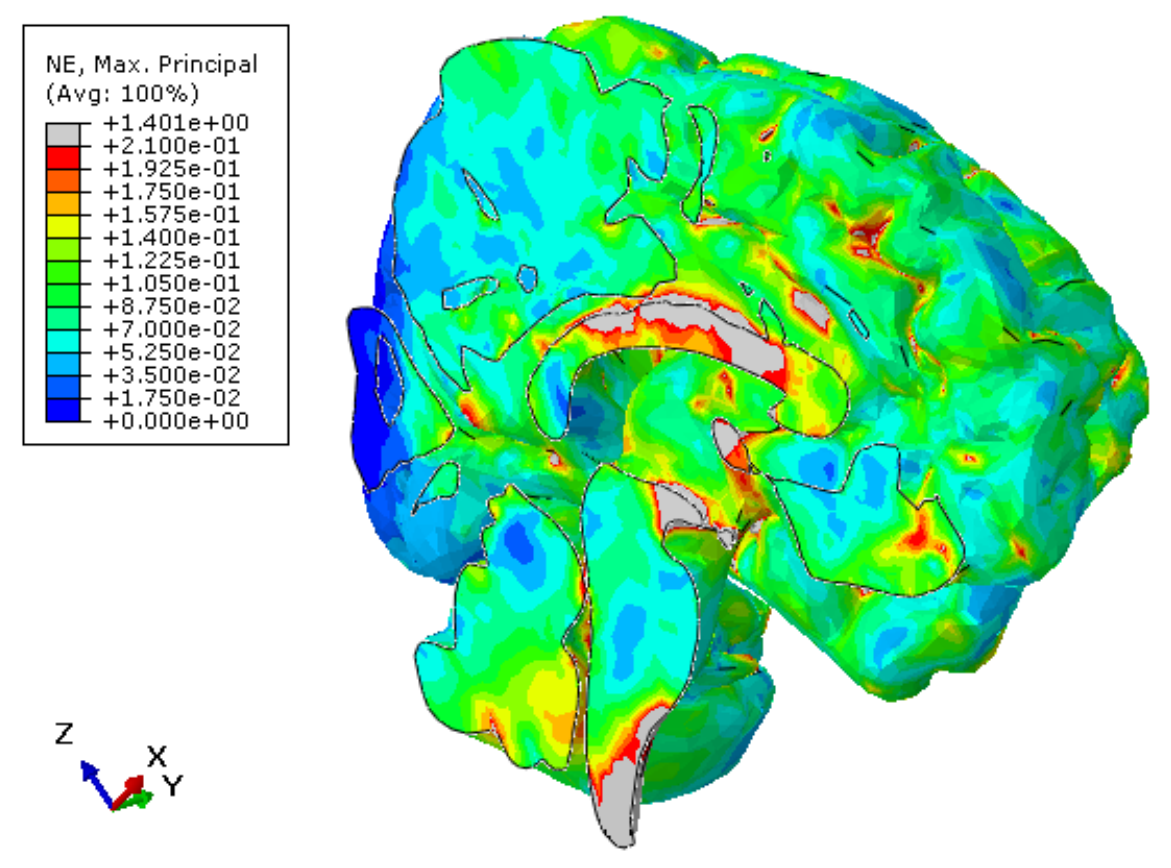

Figure 11. Sagittal plane depicting the maximum principal strain mapping (threshold of 0.21 ).

Table 10 summarises the results of this numerical evaluation. It presents the brain volume percentage where the injury thresholds were exceeded: (i) $18 \mathrm{kPa}$ of von Mises stress results in a $50 \%$ probability to occur MTBI; (ii) $173 \mathrm{kPa}$ and $235 \mathrm{kPa}$ of hydrostatic pressure for moderate and severe TBI, respectively; (iii) 0.18 of maximum principal strain for $50 \%$ probability of DAI and concussion in the corpus callosum.

The numerical results computed with the FE head model revealed the commercial C-headband as the best performer. The injury risk associated with this headband was always lower than the others. Nevertheless, the sustainable alternative, NL10 agglomerated cork, performed better than the A and $\mathrm{B}$ headbands, being lighter than the C-headband. Therefore, although the best performance was achieved by a headband composed by synthetic materials, the natural option proved to be an excellent alternative by having the closest performance to headband C. Additionally, this headband was not optimised, being designed to have similar conditions to the commercial products. Therefore, it is still possible to improve the performance of NL10 headband by carrying out a parametric study based on its geometrical design. 
Table 10. Brain volume percentage where the injury thresholds were exceeded.

\begin{tabular}{|c|c|c|c|c|}
\hline Headband & $\begin{array}{l}\text { von Mises } \\
(18 \mathrm{kPa})\end{array}$ & $\begin{array}{l}\text { Hydrostatic Pressure } \\
(173 \mathrm{kPa})\end{array}$ & $\begin{array}{l}\text { Hydrostatic Pressure } \\
(235 \mathrm{kPa})\end{array}$ & $\begin{array}{l}\text { Max. Principal Strain } \\
(0.18)\end{array}$ \\
\hline A & 0.45 & 0.61 & 0.54 & 0.04 \\
\hline B & 0.43 & 0.60 & 0.53 & 0.03 \\
\hline C & 0.31 & 0.50 & 0.42 & 0.01 \\
\hline NL10 & 0.36 & 0.55 & 0.48 & 0.02 \\
\hline
\end{tabular}

\section{Conclusions}

In a society continuously searching for new environmentally friendly and sustainable resources, a material such as cork can be a natural alternative to synthetic materials. Agglomerated cork can be produced with tailored densities, which increase the range of applications for this material [27].

In this manuscript, in order to assess the applicability of agglomerated cork as energy absorber in a headband, and simultaneously check its potential against established solutions in the market, several steps were performed. First, experimental tests were performed on different types of agglomerated cork and three commercial headbands in order to mechanically characterise the materials. Quasi-static and dynamic tests were performed to select the most promising cork agglomerates. This step ended with the numerical validation of those tests in order to choose the proper constitutive laws for each material.

The final step consisted in the creation of a finite element headband model with the help of an ECE 22.05 headform model. This virtual testing framework was used in an impact test with different energy impact values. As the wall/ground where the headform hit is analytic rigid, the impact became more severe than in a real situation, which resulted in overestimated values. However, comparison between materials was still possible.

Finally, the curves from the headform centre of mass were used to drive the YEAHM head model, in order to perform a biomechanical assessment. Concussion, DAI and MTBI thresholds were used in order to evaluate these injuries from the impacts.

It becomes evident the necessity to find a good compromise between the density of the padding material and its capacity to sustain impacts. From the three commercial solutions analysed, A-type was too light; B-type too heavy and dense; C-type showed the best compromise. Agglomerated cork-based NL10 headband provided also an interesting response, with similar or superior protection compared to commercial alternatives. Naturally, there is still room for improvements, either on the geometry, design or material.

Cork application is not limited to headbands and has the potential to be applied in other types of personal safety gear or even in other applications where its amazing characteristics and features are desirable.

Author Contributions: Conceptualization, R.J.A.d.S. and F.A.O.F.; methodology, R.J.A.d.S.; software, F.A.O.F.; validation, F.A.O.F.; formal analysis, R.J.A.d.S.; investigation, M.M.V.; resources, F.A.O.F.; data curation, R.J.A.d.S. and F.A.O.F.; writing-original draft preparation, R.J.A.d.S., M.M.V. and F.A.O.F.; writing-review and editing, R.J.A.d.S.; visualization, M.M.V.; supervision, R.J.A.d.S. and F.A.O.F. All authors have read and agreed to the published version of the manuscript.

Funding: This work was supported by the projects UIDB/00481/2020 and UIDP/00481/2020_FCT_Fundação para a Ciência e a Tecnologia; and CENTRO-01-0145-FEDER-022083-Centro Portugal Regional Operational Programme (Centro2020), under the PORTUGAL 2020 Partnership Agreement, through the European Regional Development Fund. The authors also acknowledge the support given by Fundação para a Ciência e a Tecnologia (FCT), Researcher under grant CEECIND/01192/2017.

Conflicts of Interest: The authors declare no conflict of interest.

\section{References}

1. Clay, M.B.; Glover, K.L.; Lowe, D.T. Epidemiology of concussion in sport: A literature review. J. Chiropract. Med. 2013, 12, 230-251. [CrossRef] [PubMed] 
2. Shankar, P.R.; Fields, S.K.; Collins, C.L.; Dick, R.W.; Comstock, R.D. Epidemiology of high school and collegiate football injuries in the United States, 2005-2006. Am. J. Sports Med. 2007, 35, 1295-1303. [CrossRef] [PubMed]

3. Guskiewicz, K.M.; Weaver, N.L.; Padua, D.A.; Garrett, W.E., Jr. Epidemiology of concussion in collegiate and high school football players. Am. J. Sports Med. 2000, 28, 643-650. [CrossRef] [PubMed]

4. Yard, E.E.; Comstock, R.D. Effects of field location, time in competition, and phase of play on injury severity in high school football. Res. Sports Med. 2009, 17, 35-49. [CrossRef] [PubMed]

5. Guskiewicz, K.M.; McCrea, M.; Marshall, S.W.; Cantu, R.C.; Randolph, C.; Barr, W.; Onate, J.A.; Kelly, J.P. Cumulative effects associated with recurrent concussion in collegiate football players: The NCAA Concussion Study. J. Am. Med. Assoc. 2003, 290, 2549-2555. [CrossRef] [PubMed]

6. Pellman, E.J.; Powell, J.W.; Viano, D.C.; Casson, I.R.; Tucker, A.M.; Feuer, H.; Lovell, M.; Waeckerle, J.F.; Robertson, D.W. Concussion in Professional Football: Epidemiological Features of Game Injuries and Review of the Literature-Part 3. Neurosurgery 2004, 54, 81-96. [CrossRef]

7. Schulz, M.R.; Marshall, S.W.; Mueller, F.O.; Yang, J.; Weaver, N.L.; Kalsbeek, W.D.; Bowling, J.M. Incidence and risk factors for concussion in high school athletes, North Carolina, 1996-1999. Am. J. Epidemiol. 2004, 160, 937-944. [CrossRef]

8. Marar, M.; McIlvain, N.M.; Fields, S.K.; Comstock, R.D. Epidemiology of concussions among united states high school athletes in 20 sports. Am. J. Sports Med. 2012, 40, 747-755. [CrossRef]

9. Hollis, S.J.; Stevenson, M.R.; McIntosh, A.S.; Shores, E.A.; Collins, M.W.; Taylor, C.B. Incidence, risk, and protective factors of mild traumatic brain injury in a cohort of australian nonprofessional male rugby players. Am. J. Sports Med. 2009, 37, 2328-2333. [CrossRef]

10. Hollis, S.J.; Stevenson, M.R.; McIntosh, A.S.; Li, L.; Heritier, S.; Shores, E.A.; Collins, M.W.; Finch, C.F. Mild traumatic brain injury among a cohort of rugby union players: Predictors of time to injury. Br. J. Sports Med. 2011, 45, 997-999. [CrossRef]

11. Shuttleworth-Edwards, A.B.; Noakes, T.D.; Radloff, S.E.; Whitefield, V.J.; Clark, S.B.; Roberts, C.O.; Essack, F.B.; Zoccola, D.; Boulind, M.J.; Case, S.E.; et al. The comparative incidence of reported concussions presenting for follow-up management in South African rugby union. Clin. J. Sport Med. 2008, 18, 403-409. [CrossRef] [PubMed]

12. Echlin, P.S.; Tator, C.H.; Cusimano, M.D.; Cantu, R.C.; Taunton, J.E.; Upshur, R.E.; Hall, C.R.; Johnson, A.M.; Forwell, L.A.; Skopelja, E.N. A prospective study of physician-observed concussions during junior ice hockey: Implications for incidence rates. Neurosurg. Focus 2010, 29, E4. [CrossRef] [PubMed]

13. Benson, B.W.; Mohtadi, N.G.; Rose, M.S.; Meeuwisse, W.H. Head and Neck Injuries Among Ice Hockey Players Wearing Full Face Shields. JAMA 1999, 282, 2328-2332. [CrossRef] [PubMed]

14. Hootman, J.M.; Dick, R.; Agel, J. Epidemiology of collegiate injuries for 15 sports: Summary and recommendations for injury prevention initiatives. J. Athl. Train. 2007, 42, 311-319. [PubMed]

15. Dick, R.; Hootman, J.M.; Agel, J.; Vela, L.; Marshall, S.W.; Messina, R. Descriptive epidemiology of collegiate women's field hockey injuries National Collegiate Athletic Association Injury Surveillance System, 1988-1989 through 2002-2003. J. Athl. Train. 2007, 42, 211-220. [PubMed]

16. Marshall, S.W.; Hamstra-Wright, K.L.; Dick, R.; Grove, K.A.; Agel, J. Descriptive Epidemiology of Collegiate Men's Lacrosse Injuries National Collegiate Athletic Association Injury Surveillance System, 1988-1989 Through 2003-2004. J. Athl. Train. 2007, 42, 286-294.

17. Gessel, L.M.; Fields, S.K.; Collins, C.L.; Dick, R.W.; Comstock, R.D. Concussions among United States high school and collegiate athletes. J. Athl. Train. 2007, 42, 495-503.

18. Lincoln, A.E.; Caswell, S.V.; Almquist, J.L.; Dunn, R.E.; Norris, J.B.; Hinton, R.Y. Trends in concussion incidence in high school sports: A prospective 11-year study. Am. J. Sports Med. 2011, 39, 958-963. [CrossRef]

19. Powell, J.W.; Barber-Foss, K.D. Traumatic brain injury in high school athletes. JAMA 1999, 282, 958-963. [CrossRef]

20. Castile, L.; Collins, C.L.; McIlvain, N.M.; Comstock, R.D. The epidemiology of new versus recurrent sports concussions among high school athletes, 2005-2010. Br. J. Sports Med. 2012, 46, 603-610. [CrossRef]

21. Lincoln, A.E.; Hinton, R.Y.; Almquist, J.L.; Lager, S.L.; Dick, R.W. Head, face, and eye injuries in scholastic and collegiate lacrosse: A 4-year prospective study. Am. J. Sports Med. 2007, 35, 207-215. [CrossRef] [PubMed] 
22. Agel, J.; Harvey, E.J. A 7-year review of men's and women's ice hockey injuries in the NCAA. Can. J. Surg. 2010, 53, 319-324. [PubMed]

23. Kerr, Z.Y.; Collins, C.L.; Mihalik, J.P.; Marshall, S.W.; Guskiewicz, K.M.; Comstock, R.D. Impact Locations and Concussion Outcomes in High School Football Player-to-Player Collisions. Pediatrics 2014, 134, 489-496. [CrossRef] [PubMed]

24. Fernandes, F.A.O.; Pascoal, R.J.S.; de Sousa, R.A. Modelling impact response of agglomerated cork. Mater. Des. 2014, 58, 499-507. [CrossRef]

25. Fernandes, F.A.O.; Jardin, R.T.; Pereira, A.B.; de Sousa, R.A. Comparing the mechanical performance of synthetic and natural cellular materials. Mater. Des. 2015, 82, 335-341. [CrossRef]

26. Jardin, R.T.; Fernandes, F.A.O.; Pereira, A.B.; de Sousa, R.A. Static and dynamic mechanical response of different cork agglomerates. Mater. Des. 2015, 68, 121-126. [CrossRef]

27. Santos, P.T.; Pinto, S.; Marques, P.A.A.P.; Pereira, A.B.; de Sousa, R.A. Agglomerated cork: A way to tailor its mechanical properties. Compos. Struct. 2017, 178, 277-287. [CrossRef]

28. Coelho, R.M.; de Sousa, R.A.; Fernandes, F.A.O.; Teixeira-Dias, F.M.V.H. New composite liners for energy absorption purposes. Mater. Des. 2013, 43, 384-392. [CrossRef]

29. Dassault Systèmes Simulia Corp. ABAQUS 6.10 Documentation; ABAQUS User's Manual, Version 6.10; Dassault Systèmes Simulia Corp.: Providence, RI, USA, 2010.

30. Rah, K.; Paepegem, W.V.; Habraken, A.M.; Degrieck, J.; De Sousa, R.J.A.; Valente, R.A.F. Optimal low-order fully integrated solid-shell elements. Comput. Mech. 2013, 51, 309-326. [CrossRef]

31. Van Den Bosch, H.L.A. Crash Helmet Testing and Design Specifications. Ph.D. Thesis, Technische Universiteit Eindhoven, Eindhoven, The Netherlands, 2006; doi:10.6100/IR613094. [CrossRef]

32. Fernandes, F.A.; De Sousa, R.A. Finite element analysis of helmeted oblique impacts and head injury evaluation with a commercial road helmet. Struct. Eng. Mech. 2013, 48, 661-679. [CrossRef]

33. Halstead, P.D., Alexander, C.F., Cook, E.M. and Drew, R.C. Hockey Headgear and the Adequacy of Current Designs and Standards. In Safety in Ice Hockey: Third Volume; Ashare, A., Ed.; ASTM International: West Conshohocken, PA, USA, 2000; pp. 93-100. [CrossRef]

34. Post, A.; De Grau, S.; Ignacy, T.; Meehan, A.; Zemek, R.; Hoshizaki, B.; Gilchrist, M.D. Comparison of Helmeted Impact in Youth and Adult Ice Hockey. In Proceedings of the IRCOBI Conference, Madrid, Spain, 20-22 September 2016; pp. 194-204.

35. Kendall, M.; Post, A.; Gilchrist, M.D. A comparison of dynamic impact response and brain deformation metrics within the cerebrum of head impact reconstructions representing three mechanisms of head injury in ice hockey. In Proceedings of the International Research Council on the Biomechanics of Injury Conference, Dublin, Ireland, 12-14 September 2012; Volume 40, pp. 430-440.

36. Campolettano, E.T.; Gellner, R.A.; Smith, E.P.; Bellamkonda, S.; Tierney, C.T.; Crisco, J.J.; Jones, D.A.; Kelley, M.E.; Urban, J.E.; Stitzel, J.D.; et al. Development of a Concussion Risk Function for a Youth Population Using Head Linear and Rotational Acceleration. Ann. Biomed. Eng. 2020, 48, 92-103. [CrossRef] [PubMed]

37. Allison, M.A.; Kang, Y.S.; Maltese, M.R.; Bolte, J.H.; Arbogast, K.B. Measurement of Hybrid III Head Impact Kinematics Using an Accelerometer and Gyroscope System in Ice Hockey Helmets. Ann. Biomed. Eng. 2015, 43, 1896-1906. [CrossRef] [PubMed]

38. Yoganandan, N.; Pintar, F.A. (Eds.) Frontiers in Whiplash Trauma. Clinical E Biomechanical; Volume 38 Biomedical and Health Research; IOS Press: Clifton, VA, USA, 2000; p. 590.

39. Migueis, G.F.J.; Fernandes, F.A.O.; Ptak, M.; Ratajczak, M.; de Sousa, R.A. Detection of bridging veins rupture and subdural haematoma onset using a finite element head model. Clin. Biomech. 2019, 63, 104-111. [CrossRef] [PubMed]

40. Fernandes, F.A.O.; Tchepel, D.; Alves de Sousa, R.J.; Ptak, M. Development and validation of a new finite element human head model. Eng. Comput. 2018, 35, 477-496. [CrossRef]

41. Fernandes, F.A.O.; Alves de Sousa, R.J. Head injury predictors in sports trauma-A state of the art review. Proc. Inst. Mech. Eng. Part H J. Eng. Med. 2015, 229, 592-608. [CrossRef]

(C) 2020 by the authors. Licensee MDPI, Basel, Switzerland. This article is an open access article distributed under the terms and conditions of the Creative Commons Attribution (CC BY) license (http:/ / creativecommons.org/licenses/by/4.0/). 